\title{
Research on Restricting Factors and Countermeasures of ILS Construction Based
}

\section{on E-commerce Development}

\author{
Jianhua Zhang, Mengmeng Zhang*, and Yamin Zhao \\ Management Engineering Department, Zhengzhou University, Henan Province, China \\ tjzhangjianhua@163.com \\ *Corresponding author: 2538524106@qq.com
}

Keywords: Intelligent Logistics; Intelligent Logistics information platform; Intelligent Logistics System

\begin{abstract}
The development of diversification and internationalization of E-commerce has put forward higher requirements for the quantity and quality of enterprise logistics services. The positioning and sensing technology has gradually been mature. Relying on the Internet of things, Intelligent Logistics will emerge as the time calls for. Intelligent Logistics information platform provides personalized supply chain logistics services; timely customer feedback, and effective maintenance of customers. It improves customer satisfaction, improves the efficiency of capital use and control efforts; which is more effective in promoting national economic development. Intelligent Logistics System has many problems in the actual construction. This paper, based on the overall construction, operation and maintenance of all aspects of the problems encountered by the countermeasures, attempts to ensure that the link among
\end{abstract} various links can maximize the whole system to achieve the best, so it plays an important role.

customers, then customers will not get feedback quickly and make timely improvements; Logistics alliance

\section{INTRODUCTION}

The development of E-commerce in China has experienced the period of germination and concept transmission before 1996, the initiation and exploration in 1997-2005, the development from 2006 to 2010, the strategic advancement and scale development since 2011. During this period, China's E-commerce gradually diversified, the platform tends to specialization $\mathrm{B} 2 \mathrm{~B}$, $\mathrm{B} 2 \mathrm{C}$, to $\mathrm{C} 2 \mathrm{C}$ and $\mathrm{O} 2 \mathrm{O}$ development; Platform trading commodity categori-es from home appliances, retail, clothing, daily necessities to increase a variety of even the fresh products, the formation of a comprehensive commodity coverage of sales; The sales area is internationalization, variety, and foreign transactions more multiple; The development of E-commerce also extends from the first-tier cities to the general city and further into the countryside, the city and county Ecommerce industry to vigorously promote. E-commerce applications are no longer adhered to the financial, government, manufacturing and expand to the service industry and the emerging industry. According to the data, China's E-commerce transactions in 2011 - 2016 are list as follow. 6 trillion, 7.85 trillion, 10.2 trillion, 13.4 trillion, 18.3 trillion, 22.97 trillion, We can see the rapid development of China's electricity business from the high rate(http://www.100ec-.cn,2011-2016).

At present, China's E-commerce logistics can be divided into self-distribution, third-party logistics, logistics alliance, the fourth party logistics models. China's fourth party logistics model is not really exist, and the existing mode has its own flaws: Selfdistribution requires quantity funds and manpower, lacking of professional are easy to resources waste; Third-party logistics seller can not real-time control logistics information and service quality, without directly contacting customers, it is easy to lose the old increases the difficulty of coordination between enterprises, may leak the trade secrets, and even would course inventory backlog and distribution standards or other problems(Weicheng Liu, 2015).

The emergence of E-commerce accelerate the development of logistics, the geographical distributi-on of buyers continue to expand, the timeliness and security requirements of product transport are higher on the logistics industry. Tracking equipment and personnel quality and other issues caused the difficult problems that the existing logistics industry need to overcome in the transport process, what has become a bottleneck in the rapid development of E-commerce enterprises. In order to promote the development of E-commerce better, the more effective mode of operation will become the inevitable trend of the logistics industry. With the use of mobile Internet, Internet of things, cloud computing and large data technology. In 2008 IBM put out the "Intelligent of the Earth" idea for the first time which was later borrowed to "Intelligent logistics" topics, Since its inception, the Intelligent Logistics has become the annual logistics ten hottest words with the majority of experts and scholars of great concern, many related researches also followed. Intelligent Logistics refers to applied the effective integration of Internet of things, large data analysis, perception and identification, remote monitoring and artificial intelligence technology and other technology to logistics activities each link. Through the advanced Internet of things technology, Integrating the logistics industry transport, warehousing, distribution, freight forwarding and other aspects resources, then achieving the logistics industry intelligence, automation, information operation and management. At present, the exploration of Intelligent Logistics is still in the initial stage, the Intelligent Logistics System has many issues in the physical construction, implementation of operations and follow- 
up maintenance and such as the development model, information platform construction and management system, unified system construction standards, low level using the relevant technology, Talent scarcity and so on (Guangli Shao, 2015.Yanni Li, 2016.Yuanyuan Li, 2017).

\section{CONSTRAINTS OF THE CONS-TRUCTION OF ILS}

With the rapid development of the E-commerce industry, many modern logistics systems already have the features with the integration of unified, relatively intelligent and other advanced technology; There are some enterprises of the logistics system also having used the latest infrared, laser, automatic identification, positioning, sensors, RFID, satellite positioning and other high-tech, the advanced system that is a set of light, machine, electricity, information technology in one also has some degree developed in the enterprises' daily operation. But in the every links of Intelligent Logistics System building there are still existing many following constrains what come from the external environment and logistics enterprises themselves.

\subsection{System preparation and planning link}

\subsubsection{External factors}

The existing positioning and other independent technology have been developed by leaps and bounds, but the Internet of Things system which are based on IL has not been mature yet. The standard of logistics information has always been one of the most important problems during the development of logistics industry, China's existing logistics standardization system has not been perfect, the system is more serious within the block segmentation that cause many difficulties to achieve real-time information exchanging and sharing.

\subsubsection{Internal factors}

It is all enterprises need to consider the choose that creating a new intelligent system or relatively further upgrading the old system. upgrading the old information system will have a relatively expensive transformation costs, creating a totally new intelligent logistics system needs the high standards demanding of enterprises amount of manpower, material and financial, huge pressure of business resource consumption makes some small and medium enterprises lose desire; Although updating the original system costs relative lower, however, in the era of rapid development of information environment, the system's timeliness can not have longterm protection even after the updating.

\subsection{Implementation of operational links}

\subsubsection{The lack of basic information}

The essence of a logistics system's implement-ation is integrating customer information, analyzing, managing and applying, how to dig the information that self needed in the massive data, how to allocate resources rationally, how to improve the distribution efficiency and accuracy, how to update the information in time and solve the problem quickly; Intelligent logistics information platform need to integrate the main logistics business, eliminate business can not be seamless docking, make the connected business achieve seamless docking, improve the coordination and integration capabilities of different business, and ultimately realizing the integration of logistics services and improving the overall efficiency of logistics services.

\subsubsection{The lack of high-quality talent}

Although with the rapid development of electricity and logistics industry, many institutions and schools are corresponding to set up the counterpart professional, to cultivate a number of e-commerce professionals, however, the training of talent by the University are having relatively backward knowledge and equipment, the finally graduates will are far behind the actual reality needs of the business.

In addition to the quality of graduates, as well as contemporary graduates on the job requirements and business requirements for talent is relatively different, enterprises hold three types of attitude for the general candidates: Ambitious students whose stability is not high, not considered; For the job requirements to meet a certain percentage of admission; For the ability, attitude will give grass-roots internship opportunities. The proportion of the three graduates is shown below.

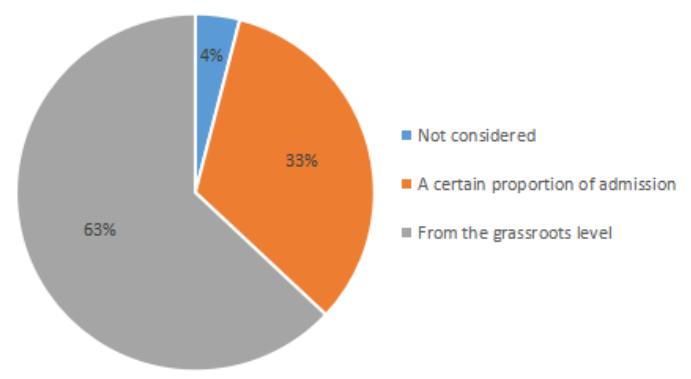

Figure 1: The proportion of enterprises to the attitude of talent

\subsection{System preparation and planning link}

\subsubsection{Hardware and software facilities' mai-ntenance and updating}

Software updates needs talent and hardware updates needs funds. In the age of rocketing development of modern technology, the life-cycle of various technology products are getting shorter and shorter, IL relying on the whole process of technology, then the most important issue of the follow-up is the regular system upgrades, to ensure the sustainable application of the system value. the maintenance and updating link of system is also one important part links of the main investment. Enterprise information management system follow-up maintenance following several pain.

(1) The pain of system's lacking of flexibility

Business environment changes, business processes are constantly changing, but the rigid information system can not change with the business process changes;

(2) The pain of the system upgrade

1) Changes in business needs: the increase in business volume, the original system can not meet the 
needs of enterprises; business process changes, or corporate mergers and acquisitions and other events will lead to the emergence of enterprise information system upgrade needs, and code secondary development Bring higher costs, and the delay in time,

2) Replacing the development language: the original changes in the hardware and software environment, the need to replace the development language; function changes, the original software development team does not exist, with the original software development costs higher than the current popular software development and other reasons, The whole system to push back, time, cost risk is very large.

3) Replace the database: the original database capacity and processing capacity can not meet the business needs of enterprises involved in the replacement of the database, may cause the risk of recode development.

4) Changes in software architecture: from $C / S$ to $B / S$ and then to the pure browser mode, software architecture changes, but also cause a huge investment in the information system.

(3) The pain of being suffered foreign software "acclimatized"

The rapid development of the Internet and the explosive growth of information, gave birth to ecommerce and supply chain management, for the provision of pre-installed software SAP, Oracle, how to change the provision of software services and delivery mode, in order to meet the enterprise customers Personality and rapid delivery of the demand, as the "orange oranges for the orange, raw for the yellow" after another major challenge. Different financial systems, different weighing system, business process differences, differences in business control, the difference between the integrity of the system led to foreign software acclimatized.

\subsubsection{The application and security of customer information}

During the Large data age, the data become the latest core competition resources of enterprise of the new generation, if one enterprises want to take advantage of the development status, it must master more information comparing with the competitors in the same time, and then making full use of the information. With the advent of various Internet fraud and other leaking information, people have more awareness on their own information security, and effective rights activists have also increased, on the one hand, enterprises need to the integrate and applying customers' information, on the other hand they have the responsibility to protect their clients information security.

\section{INTELLIGENT LOGISTICS DE-VELOPMENT COUNTERMEA-SURES}

Intelligent Logistics System has evident benefits, which integrates sensing, regular, intelligent analysis, optimization decision, system support, automatic correction and timely feedback (Hejie Zhang, 2011.). Intelligent Logistics is bound to appear, that is in line with the modern logistics industry information automation, digital network, intelligent visualization, real-time agility, tracking and intelligent control of the new development trends, and is beneficial to reduce costs, enhance aging, control risk, protect environmental and conserve energy, improve service quality. To build the Intelligent Logistics System enterprises need to combine the advantages of internal and external resources, and achieving a win-win situation with peer companies, this paper has the following suggestions.

\subsection{Combining wanted and training}

By the troubled enterprise human resources department of the problem map shows that in the enterprise human resources within the many pressures, including staff recruitment pressure, staff training and development pressure and staff turnover pressure to occupy the top three issues. For enterprises, foreign wanted talents can ensure the quantity but lack quality. while the training will cost more money and time, the internal staff of the enterprise has a better understanding degree and is easier to get started. So business people need both internal and external integration to complete its own shortcomings, forming the balance situation that internal staff lead the new staff and new staff promote the old ones.

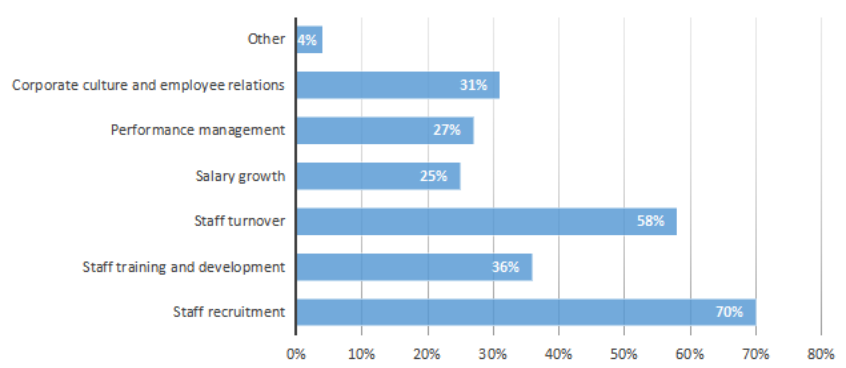

Fig. 2. The ranks of the troubles what the human resources department are facing

\subsection{Logistics enterprises cooperating and sharing}

Establishing information sharing mechanism, Intelligent Logistics information platform only become a social public platform for many logistics enterprises and customers using, that eventually can provide a whole logistics supply chain services operating platform, changing the regional logistics ecology, So that logistics enterprises and their customers or enterprises can establish an efficient operation mode with advanced information communication and standardized, efficient and further reduce the operating costs and improve profitability.

Logistics costs are high that is China's economic operation in a major problem. In 2013, China's social logistics total cost of GDP ratio of $18 \%$, nearly twice the developed countries. Then decreased year by year, to 2016 has been reduced to $14.9 \%$, but still significantly higher than the developed countries. The emergence of a shared economic model provides a new breakthrough for logistics to "reduce costs". In fact, many logistics companies are actively developing logistics sharing platform, through the sharing of the development of logistics system: on the one hand, you can make full use of existing logistics resources to improve resource 
utilization; the other hand, you can also avoid duplication of construction, investment and Maintenance caused by the waste.

\subsection{Using government policy support actively}

To further reducing the logistics cost and increasing efficiency, Government has published many related notifications, such as The State Council General Office of the State Council on the forwarding of the National Development and Reform Commission to create a good market environment to promote the development of traffic and logistics integration of the implementation of the notice, the State Council on the forwarding of the National Development and Reform Commission logistics industry efficiency special action program (2016- 2018) notice. some specific policy support is in the following.

\subsubsection{Deepening reform and stimulating the vitality}

Improving the management policy of urban distribution vehicle traffic, optimizing traffic safety and traffic control measures; and streamlining business branch offices; Deepening the reform of cargo clearance: achieving the national clearance integration, reducing compression time, speeding up the realization of one access, sharing, and free declaration by the end of 2017.

\subsubsection{Increase the intensity of tariff reduction and effectively light the burden on enterprises}

Bettering the logistics field related tax policy, fully implementing the preferential policies that are about halved the levy of urban land use tax of logistics enterprises commodity storage facilities land; determining the level of vehicle traffic charges scientifically and reasonably.

\subsubsection{Strengthen the construction of key and weak links and enhance the comprehensive service capacity}

Strengthening the planning and land support for logistics development: giving priority protection to those new logistics storage land of logistics parks which are included in National and provincial demonstration; Encourage to supply land to logistics enterprises through a variety of ways such as "first rent" and "leasing"; All localities should establish approval green channel of key logistics infrastructure construction land to improve the efficiency.

\section{CONCLUSIONS}

Intelligent Logistics is using integrated intelligent technology, so that the logistics system can mimic human intelligence, with thinking, perception, learning, reasoning and self-solve some of the problems in the logistics capacity. Obtaining and analyzing information to make decisions in the circulation process, so that commodity information from the source began to be tracked and managed to achieve faster than the real commodity flow. The construction of Intelligent Logistics System not only reduces the logistics cost and improves the profit; procurement and sales system of intelligent integration to lay the foundation; saving consumers cost, easy, rest assured that shopping; but also improving the efficiency of government departments, helping the political system reform, promoting the further development of the local economy, and enhancing the comprehensive competitiveness.

\section{ACKNOWLEDGEMENTS}

This work is supported by the Excellent Young Teacher Development Fund Project of Zhengzhou University (Foundation No.2015SKYQ15) and the Innovation and Development Fund of Zhengzhou University School of Management Engineering (Foundation No. 20170604).

\section{REFERENCES}

[1] China Electronic Commerce Research Center Ann-ual Monitoring Data [EB/OL]. http://www.100ec-.cn/detail-6398366.html, 2011-01-01/2016-12-31.

[2] Guangli Shao, 2015. Study on the Development Model of Intelligent Logistics Based on Internet of Things Technology, Logistics Engineering and Management. 37(11):111-114.

[3] Hejie Zhang, 2011. Study on the Basic Connotation and Implementation Framework of Wisdom Logistics, Market Modernization. (23):44-46.

[4] Weicheng Liu, 2015. Study on Logistics Model and Development Trend in E-commerce Environment, Logistics Technology,34(05),29-31.

[5] Yanni Li, 2016. Wisdom Logistics Reconstruct-ion of Supply Chain Value, China Foreign Investment. (23):58-59.

[6] Yuanyuan Li, 2017 Research on Intelligent Logistics Information Platform Planning, Academic Forum. 36(05):140143. 